\title{
HET GETUIGENIS AANGAANDE JEZUS EEN PNEUMATOLOGISCHE VERKENNING
}

\author{
L. Floor ${ }^{1}$ \\ ABSTRACT \\ THE TESTIMONY ON JESUS - \\ A PNEUMATOLOGICAL INVESTIGATION
}

The issue in this article is to what extent people in this postmodern era can know the real meaning about the nature of Jesus of Nazareth. In his First Epistle John answers three questions concerning this problem. How do we know that Jesus is the Son of God? How are we personally related to this extraordinary truth that Jesus of Nazareth is the Son of God? In what way should this personal relationship enter the life of those who are born again? By explaining the work of the Holy Spirit John indicates that there is a close interaction between the doctrine of Jesus the Son of God and the spiritual life of believers.

\section{INLEIDEND}

In zijn bekende boek: Geloof deur die eeue geeft Professor Schulze brede aandacht aan de persoon van Jezus Christus. Hij wijdt er zelfs een heel hoofdstuk aan. ${ }^{2}$ Schulze begint met er op te wijzen dat Jezus een enkele keer God genoemd wordt. ${ }^{3}$ Reeds eerder in zijn boek heeft hij deze stelling uitgewerkt met de woorden:

In enkele gevalle in die Nuwe Testament word Christus "God" genoem (Joh. 20:28; Rom. 9:5; 1 Joh. 5:20). Gepaard hiermee gaan die feit dat Hy aanbid is (bv. Mat. 28:9; 1 Kor. 1:2). Die Goddelike hoogheid van Christus word ook uitgedruk deur die naam Here (Kurios). Soos ons weet, het die Septuaginta die Naam van God vertaal deur Kurios. In die Nuwe Testament word hierdie benaming oorgedra op Jesus. Dit raak dan nie net sy eer nie (vgl. Jes. 45:23 met Fil. 2:10,

1 Prof. dr. L Floor, emeritusprofessor in Nuwe-Testamentiese Wetenskap, Fakulteit Teologie, PU vir CHO (Skool vir Bybelwetenskappe en Bybeltale, Fakulteit Teologie, Noordwes-Universiteit, voorheen P.U. vir C.H.O.); Van Riebeeckstraat 73, Potchefstroom, 2531.

1floor@mweb.co.za

2 Schulze, L.F., Geloof deur die eeue (Pretoria, N.G.Kerkboekhandel, $\left.{ }^{2} 1990\right)$, 69-108.

3 A.w., 71. 
11) maar ook sy werk, sodat selfs die skeppingswerk aan Jesus toegeskrywe word (vgl. Ps. 102:26 e.v. met Hebr. 1:10 e.v.). ${ }^{4}$

Nadat de jubilaris enkele Schriftgegevens over de persoon van Jezus besproken heeft, schrijft hij:

Uit hierdie enkele grepe in die Nuwe Testament is dit baie duidelik dat die Skrif Jesus Christus teken, aan die een kant as 'n ware mens net soos ons, behalwe die sonde, en aan die ander kant as veel méér as 'n mens, ja, selfs veel meer as 'n profeet en wel as die Seun van God. ${ }^{5}$

In een tijd waarin met name door de aanhangers van de Nieuwe Hervorming de godheid van Christus geloochend wordt, heeft Prof. Schulze krachtig getuigd dat de mens Jezus van Nazareth tegelijk ook de Zoon van God is. $\mathrm{Bij}$ deze krachtige uitspraak stelt Schulze meteen de vraag:

Hoe moes hierdie waarheid, bely, geformuleer en afgegrens word teenoor allerlei verkeerde opvattinge?

Als huldeblijk aan een oud-collega en uit waardering voor zijn sterk christologische geloofstandpunt wil ik op zijn vraag verder borduren. Op de volgende vragen zal dan een antwoord gezocht worden:

1. Hoe komen wij aan de weet dat Jezus werkelijk de Zoon van God is?

2. Hoe is onze persoonlijke betrokkenheid op deze geweldige waarheid dat Jezus van Nazareth de Zoon van God is?

3. Hoe moet dit in ons leven gestalte krijgen?

Op de christologische lijn van prof. Schulze wil ik daarom wat verder borduren en aantonen hoe belangrijk het in onze tijd is om aan deze belijdenis onverkort vast te houden. In verband daarmee zal aandacht gegeven worden aan het werk van de Heilige Geest in de vorm van enkele pneumatologische verkenningen. Deze verkenningen zullen gedaan worden aan de hand van de eerste brief van de apostel Johannes. Hij wijst in zijn brief op het getuigenis aangaande Jezus en hij toont aan dat de Heilige Geest hierbij een belangrijke rol speelt.

\footnotetext{
4 A.w., 33.

5 A.w., 72.

6 A.w., 72.
} 


\section{DE GROTE LES UIT HET VERLEDEN}

Uit een ver verleden wordt ons duidelijk gemaakt hoe belangrijk het is om aan de belijdenis dat Jezus de Zoon van God is vast te houden.

De oude apostel Johannes heeft een brief geschreven aan gelovigen in Klein-Azie. De eerste lezers woonden in de stad Efeze en omstreken in een polytheïstische samenleving waar ze zich als christenen moesten handhaven. Tegenover de vele aanhangers van de afgodendienst die aanspraak maken op ervaring, laat Johannes zijn lezers zien dat de ware God slechts op één manier kan worden ervaren, namelijk door geloof in Jezus Christus, de Zoon van God. Daarbij laat Johannes in zijn brief zien dat leer en leven onlosmakelijk aan elkaar verbonden zijn. Wie op het terrein van de leer dwaalt, ontspoort ook gemakkelijk op het terrein van het leven. ${ }^{7}$

\section{WIE WAREN DE WOLVEN?}

Johannes acht zich op zijn oude dag nog geroepen ernstig te waarschuwen tegen een dwaalleer die de jonge christenen bedreigt. In de gemeenschap waaraan Johannes schrijft was er onzekerheid over de vraag: wie is Jezus? Dit lijkt een moderne vraag. Maar reeds in de eerste eeuwen van de christelijke kerk was de vraag naar de identiteit van Jezus actueel. Is Hij alleen maar een mens of is Hij ook God? ${ }^{8}$

De apostel Paulus had vroeger reeds aan de ouderlingen van de kerk te Efeze geprofeteerd dat er na hem wolven zouden komen die de gemeente wilden verscheuren (Hand. 20:29-30). Later is deze waarschuwing nog eens tegenover zijn leerling Timotheüs herhaald (2 Tim. 3:1; 4:3-4). De wolven zijn gekomen. Het waren mensen die achter de geloofsopvatting dat Jezus werkelijk de Zoon van God was, een vraagteken plaatsten. ${ }^{9}$ De tegenstanders van Johannes pretendeerden ook gemeenschap met God te hebben, maar ze wilden de godheid van Christus niet aanvaarden.

7 Floor, L., De leer van Christus. Praktisch commentaar op de brieven van Johannes (Heerenveen, 2002), 29, 174.

8 McLeod, D.J., 'The Love That God Hates. A Exposition of 1 John 2:15-17', in: Emmaus Journal 1995, 3-20.

9 Potterie, I de la, 'Le Péché c'est l'iniquité (1 Joan. III.4)' in: La Nouvelle Revue Théologique 78, 1956, 785-797. 


\section{DE STRIJD TEGEN HET DWAALLEER}

De strijd tegen de dwaalleer werd door Johannes op twee terreinen gevoerd, namelijk op het gebied van de orthodoxie en dat van de orthopraxie, het terrein van de leer en van het leven. De dwaalleraars verkondigden een verkeerde christologie. En met betrekking tot de orthopraxie hielden ze er een verkeerde ethiek op na. Ze namen het met de zonde niet zo nauw. ${ }^{10}$

\subsection{Leer en leven}

Johannes laat in zijn brief zien dat leer en leven onlosmakelijk aan elkaar verbonden zijn. Wie op het terrein van de leer dwaalt, ontspoort ook gemakkelijk op het gebied van het leven. Daarom besteedt Johannes in zijn brief naast de bestrijding van de dwaalleer ook bijzondere aandacht aan het praktische leven van de christenen. Hij verbindt de praktijk van de godzaligheid met het grote dogma dat Jezus de Zoon van God is.

Hij wijst op de noodzaak van de wedergeboorte en in verband daarmee op het werk van de Heilige Gees (5:1). Wedergeboorte is een noodzakelijke voorwaarde voor het aanvaarden van de getuigenis aangaande Jezus. Tegelijk is het een voorwaarde voor de godsgemeenschap en de godservaring. Niet minder dan zeven keer wijst Johannes op het 'uit God geboren zijn' (2:29; 3:9; 4:7; 5:1 (twee keer); 5:4; 5:18).

\subsection{Drie criteria}

In zijn brief wijst Johannes drie criteria aan volgens welke ieder kan beoordelen of hij werkelijk wedergeboren is en op grond daarvan het getuigenis aangaande Jezus aanvaart: een theologisch, een moreel en een sociaal criterium. ${ }^{11}$

De eerste en belangrijkste vereiste om het getuigenis aangaande Jezus te aanvaarden, is van theologische aard. Dit betreft het geloof dat Jezus de Zoon van God is $(2: 18-27 ; 3: 22 ; 5: 10,13)$, dat Christus werkelijk in het vlees gekomen is (4:2). God kan alleen bereikt en ervaren worden door middel van Jezus Christus, de Zoon van God.

De tweede maatstaf is van morele aard. Bewaren we Gods geboden (2:36)? Doen wij de gerechtigheid? Leven wij rechtvaardig (3:7)?

10 Vorster. W.S., 'Heterodoxy in 1 John', in: Essays on the General Epistles of the New Testament, Neotestamentica 9, 1975, 87-97.

11 Stott, John R. W., The Epistles op John [Tyndale New Testament Commentaries] (Grand Rapids, 1975), 89. 
De derde maatstaf is sociaal van aard. Hebben wij de broeders werkelijk lief $(2: 7-11 ; 3: 11-18 ; 4: 7-12 ; 4: 13-21)$ ?

In 5:1-3 vat Johannes deze drie criteria anders geformuleerd nog eens samen:

het geloof dat Jezus de Zoon van God is (5:1);

het betonen van liefde aan de Vader en zijn kinderen (5:2);

het bewandelen van de weg der heiligmaking (5:3).

Geloof, liefde en gehoorzaamheid zijn de drie bepalende factoren voor het ervaren van de gemeenschap met God.

\section{DE GEEST IS DE WAARHEID}

Johannes geeft uitvoerig aandacht aan het werk van de Heilige Geest, want het is door de Geest van God dat de gelovigen de waarheid over het getuigenis aangaande Jezus aan de weet komen.

In het Evangelie van Johannes wordt de Heilige Geest de Geest der waarheid genoemd (Joh. 15:26). Hij zal van Christus die de waarheid is getuigen (Joh. 15:27).

In zijn eerste brief schrijft Johannes dat de Geest de waarheid is (1 Joh. 5:6). De Heilige Geest getuigt niet alleen van de waarheid. Hij is de waarheid in eigen Persoon, de verpersoonlijking van de waarheid, zoals Jezus ook behalve de weg en het leven ook de waarheid is (Joh. 14:6).

\section{DE ZALVING VAN DE HEILIGE GEEST}

Een merkwaardig woord waarmee Johannes zinspeelt op de Heilige Geest is de uitdrukking: 'zalving van de Heilige' (1 Joh. 2:20). In 1 Johannes 2:27 wordt het genoemd: 'de zalving die gij ontvangen hebt'.

We vinden in de commentaren een brede scala van verklaringen over dit begrip. Sommigen zien er een sacramentele rite in of een omschrijving van het evangelie of het Woord. We moeten er echter goed op letten, dat de zalving (Gr.: chrisma) onderricht geeft, kennis verstrekt. 'De zalving leert over alle dingen', zo schrijft Johannes. Dit wijst wel heel duidelik naar een persoon.

De Heilige waarnaar Johannes verwijst kan God zijn, maar ook Christus. In het licht van vers 27 is er veel voor te zeggen aan Christus te denken. Johannes noem de zalving: het chrisma van de Heilige (2:20) of de zalving van Hem (2:27). Met de Heilige wordt hier Christus bedoeld. Hij is het die 
de zalving schenkt. Daarom hebben we hier ongewijfeld bij zalving aan de Heilige Geest te denken. ${ }^{12}$

Het is Christus die de gelovigen zalft. Christus betekent Gezalfde. Hij is zelf gezalfd om anderen te zalven. In het Oude Testament werden profeten, priesters en koningen met olie gezalfd. Dikwijls vinden we dat de Heilige Geest met olie vergeleken wordt. De zalving met olie was een heenwijzing naar de zalving met de Heilige Geest. Het chrisma, de zalving, is de gave, die Christus schenkt en blijkens Johannes 15:26 en 16:7 is dit de Parakleet.

Door de zalving met de Geest weten de gelovigen de waarheid en kunnen ze de dwaalleer onderkennen. Evenals in de Parakleet-uitspraken in het Evangelie van Johannes staat het werk van de Heilige Geest hier in de contekst van het kennen. Door deze zalving zijn de gelovigen de rechte kennis deelachtig. De Heilige Geest is de grote Leraar van de kerk. Hij onderricht de gelovigen. Het 'kennen' of 'weten' is bij Johannes geen verstandelijk, onpersoonlijk kennen. Het is een bevindelijke kennis, een kennis die gemeenschap met God insluit. ${ }^{13}$

Van verschillende kanten is de vraag gesteld waarom kiest Johannes hier voor een bekende zaak zo 'n vreemde formulering: de zalving met de Heilige Geest? Er zijn exegeten die de uitdrukking chrisma afleiden van het Griekse woord voor christenen: christianoi. In Antiochië werden de gelovigen voor het eerst zo genoemd (Hand. 11:26). Andere Schriftverklaarders trekken een vergelijking met het woord antichrist. De tegenstanders hebben een antichrisma, terwijl de gelovigen het ware chrisma hebben. ${ }^{14}$ Het is ook mogelijk dat Johannes het woord zalving gebruikt, omdat de dwaalleraar hetzelfde woord gebruiken. ${ }^{15}$

Door het bezit van de Heilige Geest hebben de gelovigen kennis. Het is de zaligmakende kennis die Christus door zijn Geest schenkt. Het is de kennis dat Jezus werkelijk de Zoon van God is.

12 Hiebert, D.E., 'An Expositional Study of in John 2:18-28', in: Bibliotheca Sacra 1989, 76-93.

13 Suitbertus, A.S., 'Die Volkommensheitslehre des ersten Johannesbriefe', in: Biblia 39 (1958), 449-470.

14 Brooke, A.E., The Johannine Epistles. A critical and exegetical commentary on the Johannine Epistles [ICC] (Edinburgh, 1912), 56; Bonsirven, J., Épitres de S. Jean [Verbum Salutis IX] (Paris, 1914), 72; Thomson, M.M., '1-3 John', in: The IVP New Testament Commentary series (Leicester, 1992), 48.

15 Dodd, C.H., Commentary on the Johannine Epistles [The Mofatt New Testament Commentary] (London, 1946), 61; Schnackenburg, R., Die Johannesbriefe [Herders Theol. Kommentar zum Neuen Testament] (Freiburg-Basel-Wien, 1962), 151. 


\section{HET WAPEN VAN DE GEEST}

Johannes maakt in zijn eerste brief gebruik van een merkwaardige schrijfstijl. Hij ordent zijn gedachten volgens een bepaald patroon. Hij bespreekt een bepaald onderwerp. Stapt er plotseling van af om er later weer wat uitvoeriger op terug te komen. Deze stijl wordt wel vergeleken met een spiraal. ${ }^{16}$

Volgens zijn methode van spiraaldenken schrijft Johannes in hoofdstuk 2:26,27 weer over de zalving en dan gaat hij uitvoeriger op dit onderwerp in. Nu geeft hij aan dat deze zalving met de Heilige Geest in de gelovigen blijft en dat dit hen licht, inzicht, geeft om waarheid van dwaling te onderscheiden. De Geest is een krachtig wapen, want Hij geeft ook kracht om de dwaling te weerstaan.

De zalving met de Heilige Geest maakt ook 'dat niemand u lere'. Dit wil niet zeggen dat de gelovigen geen leerautoriteit meer nodig hebben, maar dat ze niet het oor moeten lenen aan nieuwe leerstellingen die met het gehoorde evangelie strijden. ${ }^{17}$

\section{HET GETUIGENIS VAN DE GEEST}

Geloven is niet zo gemakkelijk. De vraag is: hoe komen wij aan een waar geloof? Hoe leren wij geloven dat Jezus de Zoon van God is? Johannes heeft er reeds op gewezen dat het geloof een werk van de Heilige Geest is (5:4). Volgens zijn methode van spiraaldenken gaat hij nu verder en dieper op het werk van de Heilige Geest met betrekking tot het geloof in. Want hoe werkt de Heilige Geest? Hoe leren wij geloven dat Jezus Christus de Zoon van God is? Door het getuigenis. We hebben getuigen nodig.

Reeds in zijn Evangelie heeft Johannes er op gewezen dat geloof gegrond moet zijn op een waar, betrouwbaar getuigenis (Joh. 15:26; 20:31). In zijn brief gaat hij hier verder op in. Het is de Heilige Geest die van de waarheid getuigt. De Geest staat in zijn getuigenis niet alleen. Hij heeft twee medegetuigen: het water en het bloed en deze drie getuigen stemmen overeen, zegt Johannes (1 Joh. 5:7). De drie getuigen fungeren als een eenheid. We worden hier herinnerd aan het joodse recht, dat voorschrijft dat op de verklaring van twee of drie getuigen een zaak zal vaststaan (Deut. 19:15). Van deze drie getuigen is de Heilige Geest de belangrijkste. Johannes wijst

16 Lieau, J.M., The Theology of the Johannine Epistles (Cambridge, 1991), 4-5. LloydJones, D.M., The Love of God. Studies in 1 John (Nottingham, 1994), 117-118.

17 Calvijn, J., De Zendbrief van Johannes (Vert. A.M. Donner) (Goudriaan, 1971), 169. 
Hem aan als de Kroongetuige. ${ }^{18}$ Toch moeten wij de beide andere getuigen niet onderschatten. Johannes spreekt niet zonder reden van drie getuigen. Volgens de Statenvertaling zijn er zelfs twee keer drie getuigen, namelijk drie in de hemel en drie op de aarde. De drie hemelse getuigen in vers 7 worden in de meeste handschriften niet genoemd. Dit omstreden tekstgedeelte wordt 'De drie hemelse getuigen' of het 'Comma (= zinsnede) Johanneum' genoemd. Het is buiten het bestek van deze bijdrage om op de hele problematiek van dit tekstkritisch probleem in te gaan. ${ }^{19}$ ). De drie die op aarde getuigen, zijn de Geest, het water en het bloed (1 Joh. 5:8). Jezus, de Zoon van God is door water en bloed naar de aarde gekomen (1 Joh. 5:6). Daar zit een getuigenis in.

Over de betekenis van Jezus' komen door water en bloed lopen de meningen van de exegeten zeer uiteen. Luther en Calvijn zagen er een heenwijzing in naar de beide sacramenten: de Heilige Doop en het Heilig Avondmaal. Het is echter moeilijk vol te houden dat Jezus door de beide sacramenten van doop en avondmaal naar deze aarde is gekomen.

De meest gangbare opvatting is die van Tertullianus die het water en het bloed ziet als heenwijzing naar historische gebeurtenissen in het leven van Jezus. Zijn levensgang op aarde is langs de weg van water en bloed gegaan: het water van zijn doop en het bloed van zijn kruisdood. Dit betuigt de Heilige Geest (1 Joh. 5:6). De Geest getuigt dat het werkelijk waar is wat van Jezus gezegd wordt.

Het is opmerkelijk dat Johannes geen beroep op het Oude Testament doet om te bewijzen dat Jezus werkelijk op aarde geleefd en geleden heeft en zich ook niet beroept op zijn apostolische gezag, maar wijst op de Heilige Geest als een Kroongetuige. De lezers waren dus blijkbaar vertrouwt met de leer over de persoon en het werk van de Heilige Geest. Op zijn getuigenis kunnen we aan. De Heilige Geest is competent om te getuigen, want, zegt Johannes, de Geest is de waarheid. Dit heeft hij in zijn Evangelie ook reeds geschreven (Joh. 14:17; 15:26; 16:13).

In 1 Johannes 5:9 gaat de schrijver nog een stap verder. Hij geeft aan dat het God is die in de eerste plaats in de geschiedenis laat getuigen door het water en het bloed, dus door de levens- en stervensgang van de histo-

18 Floor, L., a.w., 153.

19 Floor, L., a.w., 155-157; Meijer, J.A., 'Goede strijd vraagt scherpe wapens. De Heilige Drieëenheid en het "Comma Johanneum”, in: De Reformatie 56 (1981), nrs. 42-43, 657-661, 673-677; Louw, A.H., 'Die drievoudige getuienis', in: Die Kerkblad, Maart 2004, no. 3161, 27-29. 
rische Jezus. En in de tweede plaats geeft God ook zijn getuigenis in de wereld en in de harten van zijn kinderen door zijn Geest. De inhoud van het getuigenis betreft Jezus Christus. God getuigt dat Hij zijn Zoon is (Mat. 3:17; 12:28-29; 17:5). Gods getuigenis geeft aan alle getuigenissen de hoogste autoriteit.

Dit getuigenis aangaande Jezus Christus moet niet iets zijn dat buiten ons leven blijft staan. Door het geloof in de Zoon van God hebben we dit getuigenis in ons, zegt Johannes (1 Joh. 5:10). Dit is het Testimonium Spiritus internum, het inwendige getuigenis van de Geest in het hart van Gods kind. ${ }^{20} \mathrm{Zij}$ die niet geloven, maken God tot een leugenaar (1 Joh. 5:10). Ongeloof is niet slechts een misverstand dat beklaagd moet worden, het is een zonde die betreurd, ${ }^{21}$ ja zelfs verafschuwd moet worden. ${ }^{22}$

Het is zeer de moeite waard het getuigenis van God door zijn Geest te aanvaarden. Wie dit getuigenis aanvaardt, heeft in Hem het eeuwige leven. Dit leven is verbonden aan de Zoon (1 Joh. 5:11). Wie de Zoon heeft die heeft het leven. Maar daar staat tegenover wie de Zoon niet heeft die heeft het leven niet. Het eeuwige leven wordt hier op aarde als geestelijk leven ervaren.

\section{SAMENVATTING}

Bij de overgang naar een nieuw millennium is het westerse denken langzamerhand overgegaan van het modernisme naar het postmodernisme. Wilde het modernisme niets van God weten en plaatste het zelfs een vraagteken achter het bestaan van God, het postmodernisme vraagt weer naar god, welke god het ook al is.

Samen met de vraag naar God, is er ook weer meer belangstelling gekomen voor Jezus. Wie is Jezus van Nazareth? Er worden vele goede dingen over Jezus gezegd en geschreven, maar dat Hij ook God zou zijn, wordt in brede kringen niet aanvaard. Daarom is de arbeid van professor Schulze met zijn sterk getuigenis dat wij de belijdenis van Jezus als de Zoon van God onverkort moeten handhaven van zeer grote en actuele betekenis. Op de moderne vraag wie Jezus is, heeft de apostel Johannes bijna tweeduizend jaar geleden een helder antwoord gegeven. Prof. Schulze heeft zich in zijn wetenschappelijke arbeid bij dat bijbelse antwoord aangesloten. Daarmee eren wij hem als een theoloog die zich het evangelie van Gods Zoon niet geschaamd heeft.

20 Brooke, A.E., a.w., 139.

21 Stott, J.R.W., The Epitles of John [Tyndale-reeks] (Grand Rapids, 1975), 182.

22 Aucamp, J.L., Die Sondeleer in die apologetiek van Dr. D. Martyn Lloyd-Jones (Bloemfontein, 2003), 118. 
Floor

Sleutelbegrippen

Christologie

Pneuma

Dwaalleer

Wedergeboorte
Het getuigenis aangaande Jezus

Trefwoorde

Keywords

Christologie

Christology

Pneuma

Pneuma

Dwaalleer

Heresy

Wedergeboorte

Rebirth 